\title{
Stem Cell Therapy for Bone and Cartilage Defects - Can Culture- expansion be Avoided?
}

\section{Elena Jones ${ }^{1 *}$ and Clara Sanjurjo-Rodriguez ${ }^{2}$}

${ }^{1}$ Leeds Institute of Rheumatic and Musculoskeletal Medicine, University of Leeds, Leeds, UK

${ }^{2}$ Rheumatology Division, INIBIC-Hospital Universitario A Coruña (CHUAC), CIBER-BBN-Cellular Therapy Area, CHUAC. Cátedra Bioibérica-University of A Coruña. A Coruña, Spain

Skeletal tissues including bone and cartilage experience significant mechanical stresses following normal physical activity. In bone, resultant microcracks are continuously repaired as a result of coordinated activity of osteoblasts, their progenitors - multipotential stromal/stem cells (MSCs) and osteo clasts, the bone-resorbing cells [1]. Physiological cartilage repair mechanisms are less well understood, but could be potentially mediated by MSCs present in cartilage superficial layer $[2,3]$, synovium $[4,5]$ or synovial fluid $[6,7]$.

Significant damages to bone and cartilage can occur as a result of acute injury (trauma) or due to chronic disease (such as osteoarthritis). In acute settings, the last two decades have witnessed a significant advance in tissue engineering approaches to repair bone in cartilage, with the use of scaffolds seeded with large numbers of culture-amplified MSCs. However, more recent research has indicated that loading scaffolds with culture-expanded stem cells may not be absolutely required, and depends on the nature and size of the defect [8,9]. This Editorial will highlight recent advances in bone and cartilage repair strategies based on enhancing the recruitment of endogenous MSCs into the defect areas.

\section{Bone Repair}

Fracture is a typical example of acute injury to bone that normally repairs itself. Non-union (failure to repair) commonly occurs when bone loss is too large (a critical-size defect) or when a patient presents with co-morbidities, such as diabetes, smoking, or high blood pressure [10]. The repair of critical-size defects requires the provision of mechanical stability and the presence of sufficient numbers of MSCs and vascular progenitors at the repair site [11].

The first successful tissue-engineering constructs to repair critical size defects in humans were based on culture-expanded bone marrow MSCs seeded on macroporous hydroxyapatite scaffolds [12]. Although they were implanted over a decade ago, the uptake of this technology in general clinical practice remains low; this is most likely due to the requirement of two surgeries (for MSC harvesting and implantation), difficulties in regulating the safety of such complex cellular products and the associated high costs of therapy. Instead, a so called Ilizarov distraction/bone transfer technique remains one of the most common methods for large defect reconstruction [13]. In basic terms, it relies on stabilizing the biomechanics and reducing the distance between the bone ends, followed by a very slow and controlled 'stretching' thus allowing a newly-formed callus tissue to be gradually vascularized and remodeled. It is believed that in this technique, the repair cells (MSCs) originate from the neighboring tissues such as periosteum [14]. As an alternative, pieces of autograft bone, containing patient's own MSCs and a bone scaffold, are placed inside the defect area; the remaining bone void is filled with a so called 'graft expander', normally a synthetic scaffold, and mechanically stabilized. Graft material can be additionally loaded with concentrated BM aspirate from the same patient in order to provide additional MSCs $[8,15,16]$.
The success of these empirical surgical approaches suggests that even for very large bone defects culture-expanding MSCs to increase their numbers million-fold may not be necessary. Instead, the provision of correct biomechanical environment seems to be the key, coupled with a scaffold that permits colonization by neighboring tissue-resident MSCs. Potent chemokine molecules such as stromal cell-derived factor 1 (SDF-1/CXCL12) and monocyte-specific chemokine 3 (MCP-3) may facilitate further recruitment of MSCs and subsequent graft vascularization in vivo [17-19]. Similar strategies based on manipulating resident MSCs for cartilage tissue regeneration are illustrated below.

\section{Cartilage Repair}

It is well-recognized that cartilage repair critically depends on the depth of a defect; full-thickness (osteochondral) defects that penetrate into the subchondral bone repair much better than partial-thickness (chondral) defects that commonly fail to repair [20]. This difference can be explained by larger numbers of MSCs present in subchondral bone $[21,22]$ as opposed to their relative paucity in cartilage $[2,3]$ or synovial fluid [6,7]. A surgical procedure called microfracture remains the gold standard for the treatment of isolated cartilage defects [23]; in this technique drilling into the subchondral bone plate creates a blood clot that is believed to have two valuable functions: first, it serves as a source of chemokines bringing subchondral bone MSCs to the repair site and second, it acts as a fibrin-based natural scaffold allowing retention, proliferation and chondrogenic differentiation of migrated MSCs [22].

Although it is generally assumed that MSCs residing in subchondral bone cavities are chiefly responsible for cartilage repair following microfracture, other joint-resident MSCs as synovium MSCs [5], synovial fluid MSCs [24] or superficial cartilage MSCs [2,3] could be also involved, particularly since these MSC types are known to possess high chondrogenic potentials $[24,25]$ and to have a direct access to cartilage. Recently, Sharma et al. [26] detected the presence of synovial fluid in the defect areas three weeks after implantation of empty hydrogel-based scaffolds, combined with microfracture, in fifteen patients with isolated cartilage lesions. MSCs injected into the

*Corresponding author: Elena Jones, Leeds Institute of Rheumatic and Musculoskeletal Medicine, Room 5.24 Clinical Sciences Building, St James's Hospital, Leeds, LS9 7TF, UK, Tel: +44 113206 5647; E-mail: msjej@leeds.ac.uk

Received January 21, 2014; Accepted January 23, 2014; Published January 25, 2014

Citation: Jones E, Sanjurjo-Rodriguez C (2014) Stem Cell Therapy for Bone and Cartilage Defects - Can Culture-expansion be Avoided? J Stem Cell Res Ther 4 e118. doi:10.4172/2157-7633.1000e118

Copyright: @ 2014 Jones E, et al. This is an open-access article distributed under the terms of the Creative Commons Attribution License, which permits unrestricted use, distribution, and reproduction in any medium, provided the original author and source are credited. 
joint space have been found in regenerated cartilage and meniscus [27], proving that these MSC could migrate through the fluid and reach the damaged areas of cartilage. Finally, the penetration of host cells into the defect site, 'assumedly from the surrounding marrow and/or synovial spaces', has been eloquently shown in Quintavalla et al. study [28].

How these endogenous MSCs are recruited into cartilage defects remains unclear. In a case of microfracture, a passive release of MSCs from the subchondral bone or the bone marrow is possible; however it is likely to be followed by their active migration driven by a simultaneous release of potent chemokine molecules into the synovial fluid [29]. Recently, several chemokines present in the synovial fluid, such as CCL25, CXCL10 and XCL1 were implicated in these migration processes [30]. Platelet-derived growth factors (PDGFs), concentrated inside the fibrin clot [31] and shown to be chemotaxic for MSCs [32], could be also involved. These PDGFs could influence MSC migration, as well as their subsequent proliferation [33], differentiation and matrix synthesis.

It can be envisaged that in principle, similar MSC migration mechanisms could be re-created with the use of 'smart' scaffolds placed in the defect site. In order to develop these new approaches, a better knowledge of the types of chemokines and their corresponding receptors on the surface of different types of MSCs is needed. For example, implantation of scaffolds loaded with TGF $\beta 3$ has led to excellent repair, by endogenous cell homing, in a rabbit model [34]. Migration of human synovial MSCs and their infiltration into similar scaffolds was improved with the creation of a stable gradient of SDF1/CXCL12 [35]. The most recent work from the same laboratory has highlighted 'the need to test multiple cytokines concurrently due to synergistic or antagonistic effects' [36].

MSCs from different tissues possess different migration potentials towards the same chemokine because they express different patterns of the corresponding chemokine receptors [37-39]. Cultured MSCs lose a full repertoire of their chemokine receptors after extensive passaging [37]. Further work is therefore needed to isolate uncultured MSCs from the joint tissues, such as synovium, and to investigate their chemokine receptor expression and the chemokine responsiveness prior to in vitro culture. This knowledge would help to design novel scaffolds, loaded with specific chemokines, in order to attract endogenous MSCs into the sites of cartilage damage.

\section{Conclusion}

Recent evidence suggests that manipulating the migration of endogenous MSCs from tissues surrounding bone or cartilage defects could represent a viable alternative to traditional tissue engineering approaches with scaffolds seeded with culture-expanded MSCs. Further work is needed to better understand the in vivo signaling mechanisms responsible for physiological chemokine releases post-injury [40] as well as to study the cellular interactions between migrated MSCs and other cells resident in damaged tissues [41].

\section{Acknowledgements}

Clara Sanjurjo-Rodriguez is beneficiary of an Erasmus fellowship from University A Coruna (Spain).

\section{References}

1. Bielby RC, Jones EA, McGonagle DG (2007) The role of mesenchymal stem cells in maintenance and repair of bone. Injury S26-32.

2. Dowthwaite GP, Bishop JC, Redman SN, Khan IM, Rooney P, et al. (2004) The surface of articular cartilage contains a progenitor cell population. $\mathrm{J}$ Cell
Sci 117: 889-897.

3. Williams R, Khan IM, Richardson K, Nelson L, McCarthy HE, et al. (2010) Identification and Clonal Characterisation of a Progenitor Cell Sub-Population in Normal Human Articular Cartilage. PLoS ONE 5: e13246.

4. De Bari C, Dell'Accio F, Tylzanowski P, Luyten FP (2001) Multipotent mesenchymal stem cells from adult human synovial membrane. Arthritis and Rheumatism 44: 1928-1942.

5. Kurth TB, Dell'Accio F, Crouch V, Augello A, Sharpe PT, et al. (2011) Functional Mesenchymal Stem Cell Niches in Adult Mouse Knee Joint Synovium In Vivo. Arthritis Rheum 63: 1289-1300.

6. Jones EA, English A, Henshaw K, Kinsey SE, Markham AF, et al. (2004) Enumeration and phenotypic characterization of synovial fluid multipotential mesenchymal progenitor cells in inflammatory and degenerative arthritis. Arthritis Rheum 50: 817-827.

7. Morito T, Muneta T, Hara K, Ju YJ, Mochizuki T, et al. (2008) Synovial fluidderived mesenchymal stem cells increase after intra-articular ligament injury in humans. Rheumatology 47: 1137-1143.

8. Dimitriou R, Jones E, McGonagle D, Giannoudis PV (2011) Bone regeneration: current concepts and future directions. BMC Medicine 9: 66.

9. Barry F, Murphy M (2013) Mesenchymal stem cells in joint disease and repair Nat Rev Rheumatol 9: 584-594.

10. Borrelli J Jr, Pape C, Hak D, Hsu J, Lin S, et al. (2012) Physiological Challenges of Bone Repair. J Orthop Trauma 26: 708-711.

11. Giannoudis PV, Einhorn TA, Marsh D (2007) Fracture heating: The diamond concept. Injury 38: S3-S6.

12. Quarto R, Mastrogiacomo M, Cancedda R, Kutepov SM, Mukhachev V, et al. (2001) Repair of large bone defects with the use of autologous bone marrow stromal cells. N Engl J Med 344: 385-386.

13. Catagni MA, Guerreschi F, Lovisetti L (2011) Distraction osteogenesis for bone repair in the 21st century: Lessons learned. Injury 42: 580-586.

14. Amir LR, Everts V, Bronckers ALJJ (2009) Bone regeneration during distraction osteogenesis. Odontology 97: 63-75.

15. Kouroupis D, Baboolal TG, Jones E, Giannoudis PV (2013) Native Multipotentia Stromal Cell Colonization and Graft Expander Potential of a Bovine Natural Bone Scaffold. J Orthop Res 31: 1950-1958.

16. Evans NR, Davies EM, Dare CJ, Oreffo ROC (2013) Tissue engineering strategies in spinal arthrodesis: the clinical imperative and challenges to clinical translation. Regen Med 8: 49-64.

17. Ito $H(2011)$ Chemokines in mesenchymal stem cell therapy for bone repair: a novel concept of recruiting mesenchymal stem cells and the possible cell sources. Mod Rheumatol 21: 113-121.

18. Shinohara K, Greenfield S, Pan H, Vasanji A, Kumagai K, et al. (2011) Stromal Cell-Derived Factor-1 and Monocyte Chemotactic Protein-3 Improve Recruitment of Osteogenic Cells into Sites of Musculoskeletal Repair. J Orthop Res 29: 1064-1069.

19. Cuthbert RJ, Churchman SM, Tan HB, McGonagle D, Jones E, et al. (2013) Induced periosteum a complex cellular scaffold for the treatment of large bone defects. Bone 57: 484-492.

20. Yamamoto T, Wakitani S, Imoto K, Hattori T, Nakaya H, et al. (2004) Fibroblas growth factor-2 promotes the repair of partial thickness defects of articular cartilage in immature rabbits but not in mature rabbits. Osteoarthritis Cartilage 12: $636-641$.

21. Jones E, English A, Churchman SM, Kouroupis D, Boxall SA, et al. (2010) Large-scale extraction and characterization of CD271+ multipotential stromal cells from trabecular bone in health and osteoarthritis: implications for bone regeneration strategies based on uncultured or minimally cultured multipotential stromal cells. Arthritis Rheum 62: 1944-1954.

22. Min B-H, Choi WH, Lee YS, Park SR, Choi BH, et al. (2013) Effect of Different Bone Marrow Stimulation Techniques (BSTs) on MSCs Mobilization. J Orthop Res 31: 1814-1819.

23. Mollon B, Kandel R, Chahal J, Theodoropoulos J (2013) The clinical status of cartilage tissue regeneration in humans. Osteoarthritis Cartilage 21: 1824 1833. 
Citation: Jones E, Sanjurjo-Rodriguez C (2014) Stem Cell Therapy for Bone and Cartilage Defects - Can Culture-expansion be Avoided? J Stem Cell Res Ther 4: e118. doi:10.4172/2157-7633.1000e118

Page 3 of 3

24. Jones EA, Crawford A, English A, Henshaw K, Mundy J, et al. (2008) Synovial fluid mesenchymal stem cells in health and early osteoarthritis: detection and functional evaluation at the single-cell level. Arthritis Rheum 58: 1731-1740.

25. Sakaguchi Y, Sekiya I, Yagishita K, Muneta T (2005) Comparison of human stem cells derived from various mesenchymal tissues - Superiority of synovium as a cell source. Arthritis Rheum 52: 2521-2529.

26. Sharma B, Fermanian S, Gibson M, Unterman S, Herzka DA, et al. (2013) Human Cartilage Repair with a Photoreactive Adhesive-Hydrogel Composite. Sci Transl Med 5: 167ra6.

27. Murphy JM, Fink DJ, Hunziker EB, Barry FP (2003) Stem cell therapy in a caprine model of osteoarthritis. Arthritis Rheum 48: 3464-3474.

28. Quintavalla J, Uziel-Fusi S, Yin JY, Boehnlein E, Pastor G, et al. (2002) Fluorescently labeled mesenchymal stem cells (MSCs) maintain multilineage potential and can be detected following implantation into articular cartilage defects. Biomaterials 23: 109-119.

29. Endres M, Neumann K, Haeupl T, Erggelet C, Ringe J, et al. (2007) Synovial fluid recruits human mesenchymal progenitors from subchondral spongious bone marrow. J Orthop Res 25: 1299-1307.

30. Endres M, Andreas K, Kalwitz G, Freymann U, Neumann K, et al. (2010) Chemokine profile of synovial fluid from normal, osteoarthritis and rheumatoid arthritis patients: CCL25, CXCL10 and XCL1 recruit human subchondral mesenchymal progenitor cells. Osteoarthritis Cartilage 18: 1458-1466.

31. Lee JW, Kwon OH, Kim TK, Cho YK, Choi KY, et al. (2013) Platelet-rich plasma: quantitative assessment of growth factor levels and comparative analysis of activated and inactivated groups. Arch Plast Surg 40: 530-535.

32. Caplan AI, Correa D (2011) PDGF in Bone Formation and Regeneration: New Insights into a Novel Mechanism Involving MSCs. J Orthop Res 29: 1795-1803.
33. Gronthos S, Simmons PJ (1995) The Growth-Factor Requirements Of Stro1-Positive Human Bone-Marrow Stromal Precursors Under Serum-Deprived Conditions In-Vitro. Blood 85: 929-940.

34. Lee CH, Cook JL, Mendelson A, Moioli EK, Yao H, et al. (2010) Regeneration of the articular surface of the rabbit synovial joint by cell homing: a proof of concept study. Lancet 376: 440-448.

35. Mendelson A, Frank E, Allred C, Jones E, Chen M, et al. (2011) Chondrogenesis by chemotactic homing of synovium, bone marrow, and adipose stem cells in vitro. FASEB J 25: 3496-3504.

36. Mendelson A, Cheung YK, Paluch K, Chen M, Kong K, et al. (2013) Competitive stem cell recruitment by multiple cytotactic cues. Lab Chip 13: 1156-1164.

37. Honczarenko M, Le Y, Swierkowski M, Ghiran I, Glodek AM, et al. (2006) Human Bone Marrow Stromal Cells Express a Distinct Set of Biologically Functional Chemokine Receptors. Stem Cells 24: 1030-1041.

38. Ringe J, Strassburg S, Neumann K, Endres M, Notter M, et al. (2007) Towards in situ tissue repair: Human mesenchymal stem cells express chemokine receptors CXCR1, CXCR2 and CCR2, and migrate upon stimulation with CXCL8 but not CCL2. J Cell Biochem 101: 135-146.

39. Stich S, Loch A, Leinhase I, Neumann K, Kaps C, et al. (2008) Human periosteum-derived progenitor cells express distinct chemokine receptors and migrate upon stimulation with CCL2, CCL25, CXCL8, CXCL12, and CXCL13. Eur J Cell Biol 87: 365-376.

40. Dell'Accio F, De Bari C, El Tawil N, Barone F, Mitsiadis T, et al. (2006) Activation of WNT and BMP signaling in adult human articular cartilage following mechanical injury. Arthritis Res Ther 8: R139.

41. Richter W (2009) Mesenchymal stem cells and cartilage in situ regeneration. $J$ Intern Med 266: 390-405. 